Research, part of a Special Feature on Effects of Roads and Traffic on Wildlife Populations and Landscape Function

\title{
Frogs Call at a Higher Pitch in Traffic Noise
}

\author{
$\underline{\text { Kirsten M. Parris }}^{1,2}, \underline{\text { Meah Velik-Lord }}^{1}$, and $\underline{\text { Joanne M. A. North }}^{1}$
}

\begin{abstract}
Male frogs call to attract females for mating and to defend territories from rival males. Female frogs of some species prefer lower-pitched calls, which indicate larger, more experienced males. Acoustic interference occurs when background noise reduces the active distance or the distance over which an acoustic signal can be detected. Birds are known to call at a higher pitch or frequency in urban noise, decreasing acoustic interference from low-frequency noise. Using Bayesian linear regression, we investigated the effect of traffic noise on the pitch of advertisement calls in two species of frogs, the southern brown tree frog (Litoria ewingii) and the common eastern froglet (Crinia signifera). We found evidence that $L$. ewingii calls at a higher pitch in traffic noise, with an average increase in dominant frequency of $4.1 \mathrm{~Hz} / \mathrm{dB}$ of traffic noise, and a total effect size of $123 \mathrm{~Hz}$. This frequency shift is smaller than that observed in birds, but is still large enough to be detected by conspecific frogs and confer a significant benefit to the caller. Mathematical modelling predicted a $24 \%$ increase in the active distance of a L. ewingii call in traffic noise with a frequency shift of this size. Crinia signifera may also call at a higher pitch in traffic noise, but more data are required to be confident of this effect. Because frog calls are innate rather than learned, the frequency shift demonstrated by $L$. ewingii may represent an evolutionary adaptation to noisy conditions. The phenomenon of frogs calling at a higher pitch in traffic noise could therefore constitute an intriguing trade-off between audibility and attractiveness to potential mates.
\end{abstract}

Key Words: acoustic interference; ambient noise; amphibian decline; animal behavior; bioacoustics; road ecology; signal design; traffic noise; urban ecology; vocal communication; Litoria ewingii; Crinia signifera

\section{INTRODUCTION}

Roads cover a significant and increasing proportion of the earth's landscape. Many ecological effects of roads have been identified, such as loss and fragmentation of habitat; pollution of air, water, and soil; mortality of animals hit by passing vehicles; and acoustic interference caused by traffic noise (Forman et al. 2003, Warren et al. 2006). The noise of passing traffic can extend more than $4 \mathrm{~km}$ from a road, depending on the volume and speed of traffic and the prevailing weather conditions (Department of Transport Welsh Office 1988). A variety of responses to road-traffic noise has been observed in birds, including singing at a higher pitch; singing louder, i.e., the Lombard effect; and changing diurnal singing patterns to avoid peak traffic periods (e.g., Slabbekoorn and Peet 2003, Brumm 2004, Fuller et al. 2007). However, the responses of other acoustically communicating animals have received little attention (Barrass 1985, Sun and Narins 2005). Sun and Narins (2005) demonstrated that motorcycle noise changed the chorusing behavior of a mixed-species community of frogs, with three species decreasing their calling rates and one species increasing its calling rate in response to the noise. The overall effect was to change the proportion of time each species spent calling, and potentially their relative breeding success (Sun and Narins 2005). A recent laboratory study found that road-traffic noise interfered with perception of the advertisement call of the grey treefrog ( Hyla chrysoscelis) by females, as shown by a reduced ability to orient toward the call in the presence of noise (Bee and Swanson 2007). Decreases in the species richness and relative abundance of frogs have been observed hundreds of meters away from a highway in eastern Ontario, Canada (Eigenbrod et al. 2009). 
Frog calls are considered to be innate rather than learned and, compared to the acoustic signals of other vertebrate groups such as songbirds and primates, they are generally simple and highly stereotyped (Hauser 1996). Male frogs call to attract females for mating and to declare to other males that a calling site or territory is occupied. The advertisement or mating call of a frog contains key information about species identity and an individual's motivation to reproduce (Giacoma and Castellano 2001). Both females and males use the spectral and temporal properties of calls to assess conspecifics during breeding (Wells 1977, Sullivan et al. 1996, Giacoma and Castellano 2001). Females are known to select mates on the basis of call properties such as frequency or pitch, pulse rate, amplitude, call rate, or call length (Sullivan 1983, Asquith and Altig 1990, Ovaska and Rand 2001, Gerhardt and Huber 2002). The first two properties are known as static properties, because they tend to vary less within individuals than the other, more dynamic properties of a call (Gerhardt 1991). In general, female frogs prefer calls that are energetically costly to produce. These could include calls that are louder, longer, and/or have a higher repetition rate, i.e., calls with high values for dynamic properties (Gerhardt and Huber 2002). A male producing energetically costly calls indicates that he has substantial energy reserves and is therefore healthy and vigorous, with access to highquality resources (Sullivan 1992, Mitchell 2001). Fitness benefits arising from mating with a male that produces energetically costly calls include higher rates of fertilization in Spea multiplicata (Pfennig 2000), faster-growing offspring in Hyla versicolor (Welch et al. 1998), and access to higher-quality nesting sites in Pseudophryne bibronii (Mitchell 2001). In addition to a preference for energetically costly calls, female frogs of some species prefer lower-frequency calls (e.g., Zweifel 1968, Ryan 1986, Pombal et al. 1994, Wollerman 1998, Felton et al. 2006), which may indicate larger body size and/or older, more experienced males. Felton et al. (2006) found that older, larger males of Cophixalus ornatus had lower-frequency calls that were more attractive to females than the calls of younger, smaller males. Older males were more likely than younger males to construct a nest that females found suitable for oviposition.

Male frogs use call characteristics that infer body size, strength, and/or willingness to fight to assess the threat posed by other males (Ramer et al. 1983, Wagner 1989, Schwartz 2001). Vocal exchanges between males may precede physical exchanges such as bouts of wrestling (Fellers 1979, Wagner 1989). During vocal exchanges, males of some species may change certain characteristics of their advertisement calls, including amplitude, duration, and calling rate (Schwartz 2001). A few species are known to lower the frequency of their advertisement calls by up to $180 \mathrm{~Hz}$ when they hear other males calling nearby (e.g., Wagner 1989, Howard and Young 1998, Given 1999, Bee et al. 2000, Giacoma and Castellano 2001, Owen and Gordon 2005), even though call frequency is generally considered to be a static property (Gerhardt 1991). Such changes to the advertisement call are likely to be short-lived because they would be energetically costly to maintain over long periods.

The active distance of an acoustic signal is the distance over which it can be detected by a conspecific (Marten and Marler 1977). It varies with a range of factors including call amplitude, call frequency, the relative positions of the caller and receiver, habitat, background noise, and the auditory acuity of the receiver (Marten and Marler 1977, Parris 2002). For example, the southern brown tree frog (Litoria ewingii) from southern Australia has a hearing threshold of $55 \mathrm{~dB}$ soundpressure level (SPL) at the average dominant frequency of its advertisement call in the absence of background noise (Loftus-Hills and Johnstone 1969, Loftus-Hills 1973). Assuming attenuation by spherical spreading alone, the active distance of its call would be approximately $100 \mathrm{~m}$ at the peak call amplitude of $101 \mathrm{~dB}$ SPL at $50 \mathrm{~cm}$ (Loftus-Hills and Littlejohn 1971). In contrast, the common eastern froglet (Crinia signifera) has a hearing threshold of approximately $75 \mathrm{~dB}$ SPL at the average dominant frequency of its advertisement call (Loftus-Hills 1973). This corresponds to an active distance of only $3 \mathrm{~m}$ at the peak call amplitude of $90 \mathrm{~dB}$ SPL (LoftusHills and Littlejohn 1971).

Acoustic interference, also known as masking, occurs when background noise reduces the active distance of a signal (Brumm and Slabbekoorn 2005). The noise of other chorusing frogs and insects can hinder mate choice by female frogs (Gerhardt and Klump 1988) and interfere with territorial interactions between males (Paez et al. 1993). Acoustic interference from natural sources of noise could lead to the modification of calls through selection for more efficient communication (Littlejohn 1965), and acoustic interference from human-generated noise may act similarly (Katti and 
Warren 2004, Warren et al. 2006). Frogs are likely to experience acoustic interference from traffic noise when calling at breeding sites close to roads (Bee and Swanson 2007). Because most of the energy in traffic noise is concentrated in the lower part of the frequency spectrum below $2 \mathrm{kHz}$, higherpitched signals may suffer less acoustic interference from traffic noise than lower-pitched signals (Brumm 2006, Warren et al. 2006). Calling is energetically expensive for frogs (Mac Nally 1981, Prestwich 1994), and the energetic cost of calling increases exponentially with call amplitude or loudness (Parris 2002). Therefore, one might expect frogs to call at a higher pitch rather than calling louder to reduce acoustic interference from traffic noise, i.e., to demonstrate a frequency shift rather than an amplitude shift (Warren et al. 2006) in response to noise.

Amphibians are an important component of many ecosystems from the tropics to the temperate zone (Heyer et al. 1994), occupying an intermediate trophic position in both their larval or aquatic and their adult or terrestrial life phases. They act both as important predators of invertebrates such as locusts and other crop pests and as prey for a wide range of species including aquatic invertebrates, fish, reptiles, and birds. Amphibians around the world are facing an extinction crisis, with almost one in three species considered to be threatened by processes such as the loss and fragmentation of habitat, disease, pollution, and pressure from introduced predators such as fish (Stuart et al. 2004, Halliday 2008). Given the large proportion of the earth's terrestrial surface that is currently affected by road-traffic noise, increasing traffic volumes, and the expected future expansion of the road network (Forman et al. 2003), many frog populations around the world are likely to be affected by traffic noise as well. Although not the most obvious potential threat to the persistence of frogs, traffic noise is one of the most geographically widespread.

In this study, we investigate the impact of traffic noise on acoustic communication in two common species of frogs, Litoria ewingii (Family Hylidae) and Crinia signifera (Family Myobatrachidae), in southern Victoria, Australia. Both are prolonged breeders, with males attending a breeding site over an extended period in winter and spring. Specifically, we investigate whether the frequency of their advertisement calls changes with increasing traffic noise. Second, we compare the size of the observed changes with those reported in birds. Although frog calls are considered to be innate, songbirds learn their songs from parents, neighbors, and flock members (Hultsch and Todt 2004). Songbirds may therefore be expected to show a faster and/or larger frequency shift in response to acoustic masking by traffic noise than frogs. Third, we estimate how the observed frequency shift in $L$. ewingii would affect the active distance of its advertisement call in traffic noise. Finally, we explore the possible mechanisms underlying an increase in the frequency of frog calls with traffic noise and discuss its potential consequences for the ecology, evolution, and conservation of frogs in noisy urban habitats.

\section{METHODS}

\section{Call recordings}

We collected digital recordings of the advertisement calls of $L$. ewingii and $C$. signifera at 47 lentic water bodies including ponds, lakes, dams, and quiet pools within streams in southern Victoria, Australia, with varying exposure to traffic noise (Fig. 1). The water bodies and surrounding roads had all been in place for at least 20 years, such that the resident frog populations had been exposed to traffic noise over multiple generations. Most study sites were located in public parks and gardens, with a few on private land. The landscape context of the sites ranged from urban and suburban Melbourne, a large city with a population of 3.5 million people, to rural areas dominated by grassland or forest. The smallest pond was approximately $25 \mathrm{~m}^{2}$ in area, whereas the largest lake was approximately $12 \mathrm{~km}^{2}$. The sites were located at least $1 \mathrm{~km}$ apart in an effort to ensure independence. We recorded for $5 \mathrm{~min}$ at each site between 2000 and 0200 using a Marantz PMD670 (Longford, UK) portable solid-state digital recorder and a matched pair of Røde NT5 (Sydney, Australia) cardioid condenser microphones set $25-30 \mathrm{~cm}$ above the ground. One microphone was directed at the calling frogs, and the other was directed at the main source of traffic noise. The recordings had a sampling frequency of $48 \mathrm{kHz}$. During recording, we also measured average, $\mathrm{C}$-weighted ambient noise using a Digitech QM 1588 sound-level meter on its fast setting directed at the main source of traffic noise. Two sites with only one individual of $C$. signifera calling were excluded from statistical analysis. In total, we included 1000 calls of $L$. ewingii across 24 study sites and the calls of 442 
individuals of $C$. signifera across 28 study sites in our analysis. The two frog species were sympatric at seven sites. Most sites were sampled only once, i.e., with one 5-min recording, but two of the 24 sites with $L$. ewingii and two of the 28 sites with $C$. signifera were sampled twice.

\section{Measurements of body size in Litoria ewingii}

There is an inverse correlation between body size and call frequency in many anuran species, with larger males producing lower-frequency calls (Wells 2007). If males were systematically smaller at noisier sites, this would lead to an increase in average call frequency with increasing traffic noise. To make a preliminary analysis of the distribution of body sizes at sites with different levels of traffic noise, we caught and measured the snout-vent length of $L$. ewingii at a subset of sites. Because $L$. ewingii was often chorusing during sound recording, it was not possible to ascertain the body size of the frogs that made particular calls. Instead, we captured and measured as many calling frogs as possible following recording to obtain a populationlevel estimate of body size. We caught and measured 63 individuals across 12 sites.

\section{Estimation of traffic noise}

At many of the study sites, frogs chorused continuously throughout the period of recording. This meant that the noise levels measured using the second of the paired microphones and the soundlevel meter often included a significant component of frog-call noise. To circumvent this problem, we estimated the level of traffic noise at each site using the Calculation of Road Traffic Noise (CoRTN) model (Department of Transport Welsh Office 1988). The noise level was expressed as $\mathrm{L}_{10} 18 \mathrm{hr}$ $\mathrm{dB}(\mathrm{A})$ SPL, which is the 90th percentile of the distribution of traffic noise experienced in the $18 \mathrm{hr}$ from 0600 to 2400 . The estimated traffic-noise levels at our study sites ranged from 47.6 to 77.0 $\mathrm{L}_{10} 18 \mathrm{hr} \mathrm{dB}(\mathrm{A}) \mathrm{SPL}$ at sites with $L$. ewingii and 43.3 to $79.3 \mathrm{~dB}(\mathrm{~A}) \mathrm{SPL}$ at sites with $C$. signifera. The 12 sites at which we measured the body size of L. ewingii had traffic-noise levels ranging from 47.6 to $68.1 \mathrm{~dB}(\mathrm{~A}) \mathrm{L}_{10} 18 \mathrm{hr}$ SPL. The quietest sites were located far from busy roads in rural locations, whereas the noisiest site was located $40 \mathrm{~m}$ from the Eastern Freeway in Melbourne, an eight-lane dualcarriageway that carries 130,000 vehicles per day.

\section{Analysis of calls}

We analyzed the frog calls in Adobe Audition 2.0 to determine the dominant frequency of the $L$. ewingii calls and the lower and upper peaks of the C. signifera calls (Littlejohn and Wright 1997) using a Blackman-Harris window and a fast Fourier transformation (FFT) length of 1024. The advertisement call of $L$. ewingii comprises a series of similar, rapidly repeated narrowband notes with a dominant frequency of approximately $2.2-2.6 \mathrm{kHz}$ (Littlejohn 1965; Fig. 2; Appendix 1). The dominant or carrier frequency is the frequency containing the greatest amount of acoustical energy. The advertisement call of $C$. signifera is a short, repeated chirp (Littlejohn 1964) that covers a broad spectral band from 2 to $5 \mathrm{kHz}$, with two distinct peaks (Fig. 3; Appendix 2). Because the dominant frequency of the call is sometimes in the lower peak and sometimes in the upper, we analyzed the two peaks separately. We expected the lower peak or lower frequency to suffer greater acoustic interference from traffic noise and therefore demonstrate a larger change with traffic noise than the upper peak or upper frequency. During this study, single advertisement calls of $L$. ewingii and $C$. signifera lasted an average of 2.6 and $0.2 \mathrm{sec}$, respectively.

\section{Statistical framework}

The use of null-hypothesis significance testing in ecology is problematic for a number of reasons (Johnson 1999, Anderson et al. 2000, McCarthy 2007). The null hypotheses chosen by researchers, e.g., that there is no effect of $x$ on species $y$, often make no biological sense; the Type I error rate $(\alpha)$ is set arbitrarily; and statistical power, or the probability of detecting an effect with the available data set, is often ignored. Furthermore, ecologists commonly misinterpret the results of statistical tests, equating statistical significance with biological significance, and/or considering the absence of a statistically significant effect as evidence of no effect (Johnson 1999, Anderson et al. 2000, Fidler et al. 2006). Presenting effect sizes with some measure of variance or precision, such as confidence intervals, is generally more informative than presenting $p$ values alone, and enables the results of a study to be included in future meta-analyses (Anderson et al. 2000, Fidler et al. 2006). We used a Bayesian framework for our statistical analyses, with an emphasis on effect sizes and precision. This enabled us to include existing, 
Fig. 1. Maps of the study area. (A) Map of Australia showing the location of the study area in southern Victoria (open square). (B) Close-up of the study area showing the location of the study sites (green circles), the central business district of Melbourne, and the town of Macedon (black squares).

A

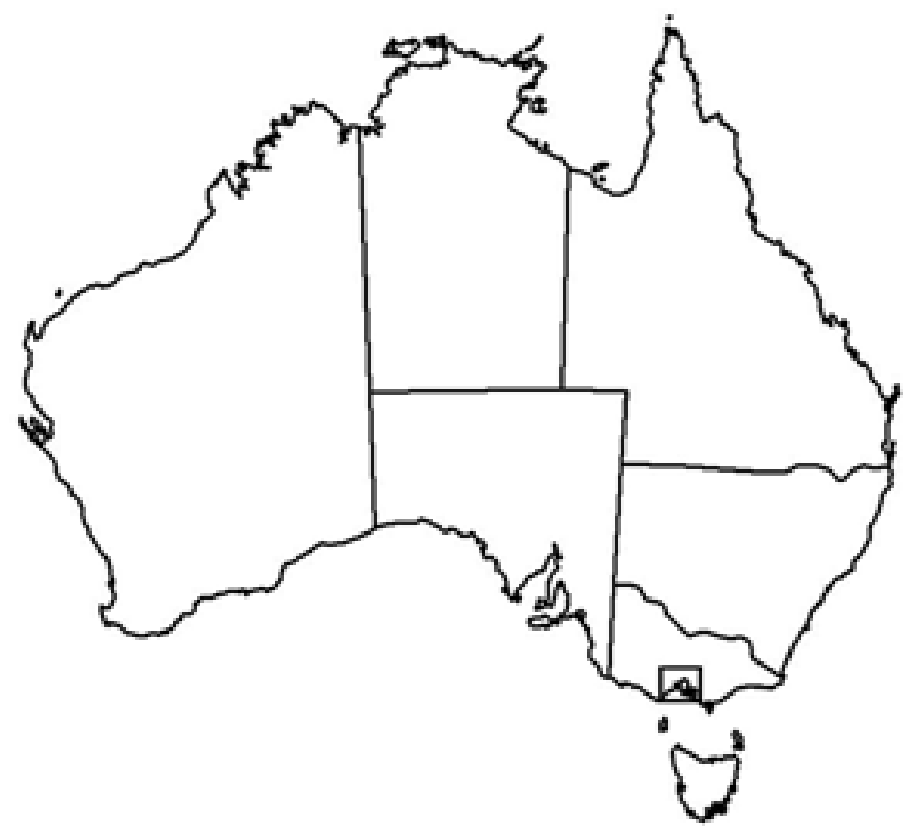

B

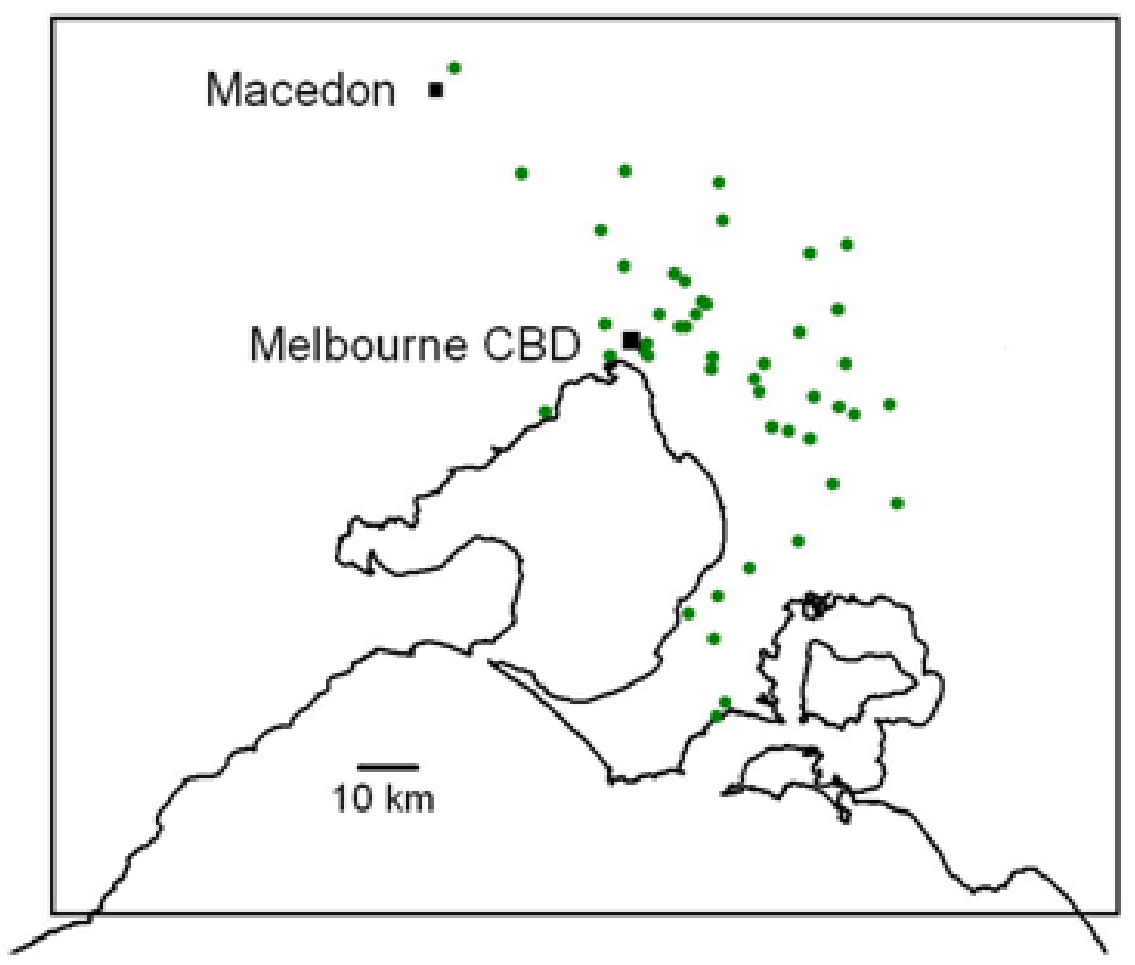


Fig. 2. Oscillogram, sonogram, and power spectrum of the call of Litoria ewingii, recorded at a wet bulb temperature of $13.5^{\circ} \mathrm{C}$. The arrow on the power spectrum shows the dominant frequency (df) of the call.
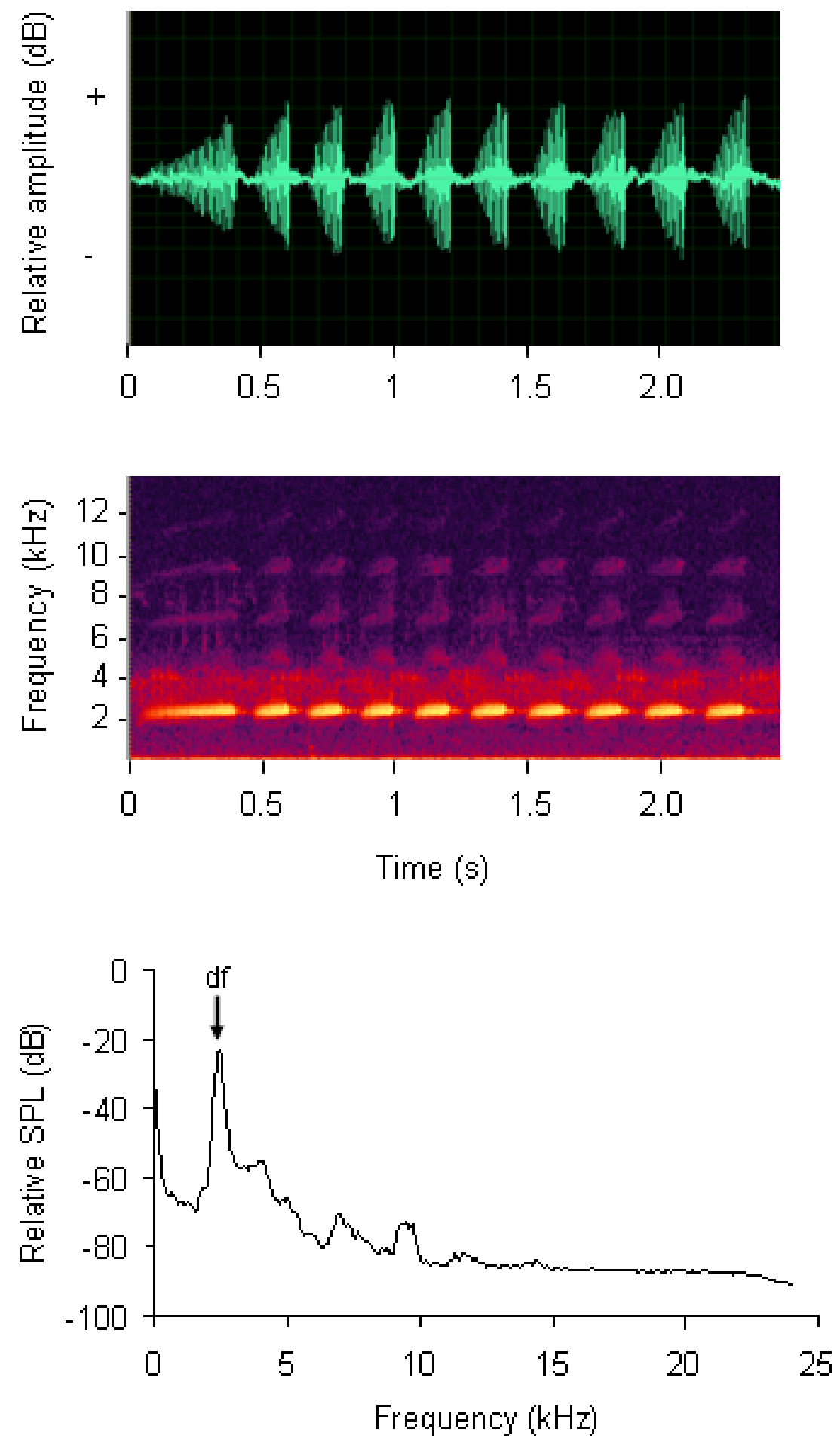
Fig. 3. Oscillogram, sonogram, and power spectrum of the call of Crinia signifera, recorded at a water temperature of $15.6^{\circ} \mathrm{C}$. The two arrows on the power spectrum show the lower frequency (lf) and upper frequency (uf) of the call.
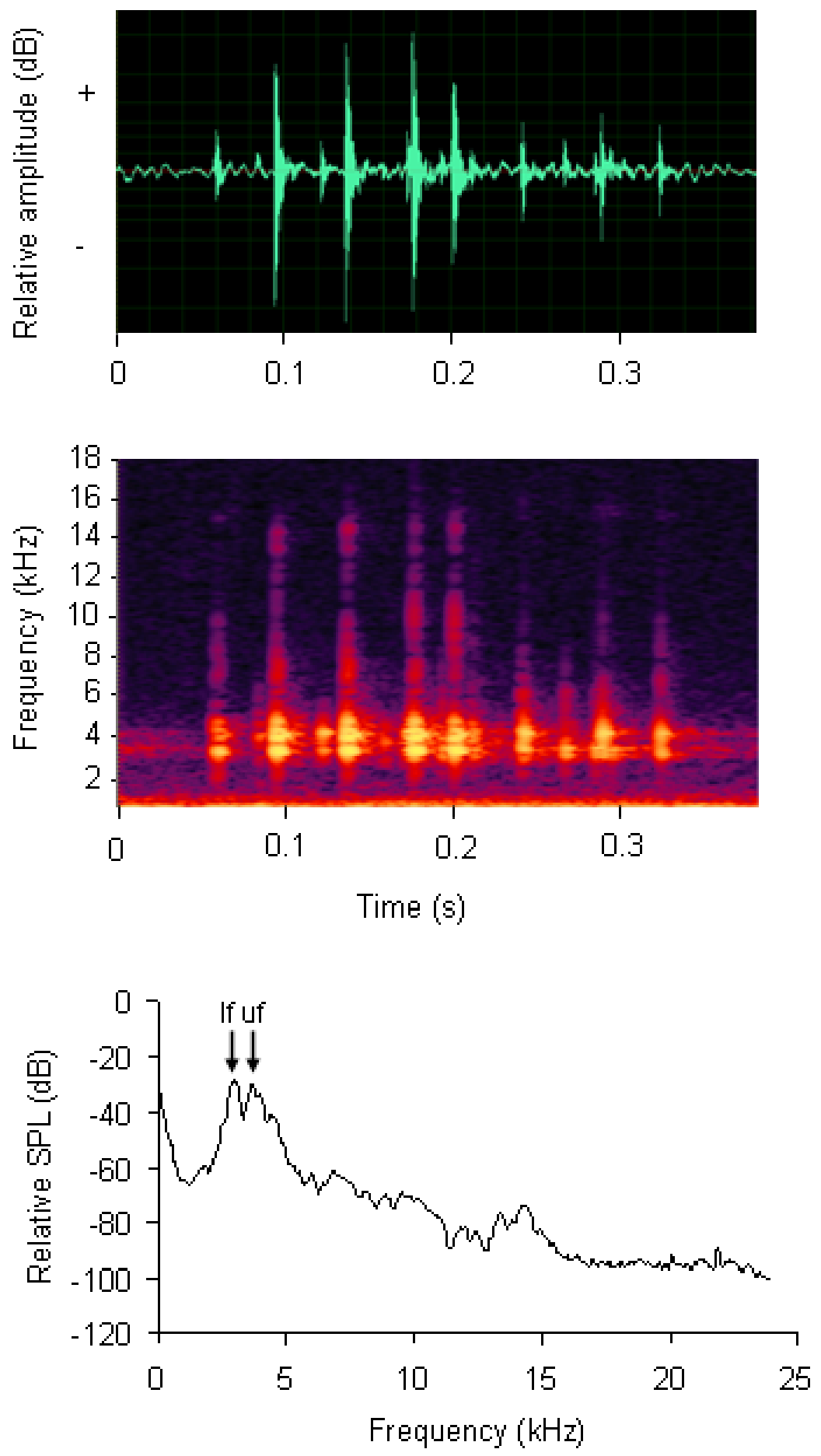
i.e., prior, information on the relationship between call frequency and temperature in Litoria ewingii and to estimate traffic volumes for some roads near the study sites for which data were missing. The Bayesian framework is also well-suited to analyzing hierarchical models that include random and fixed effects (Clark 2005). Because our models included prior information, missing data, and a hierarchical structure, they could not be analyzed using any other statistical approach. In Bayesian statistics, estimates of parameters are described by posterior density functions or probability distributions, representing the uncertainty in the estimates. These posterior distributions are obtained by combining prior information, if it exists, with new data (McCarthy 2007). The individual contributions of the prior data and the new data to the posterior distribution depend on the precision of each estimate.

\section{Statistical modeling}

\section{Effect of traffic noise on body size in Litoria ewingii}

We used hierarchical Bayesian linear regression in OpenBUGS 2.20 (Spiegelhalter et al. 2006, McCarthy 2007) to model the effect of traffic noise on body size in L. ewingii. The regression model included flat, i.e., uninformative, priors to reflect an absence of prior information, and a random site effect to account for variation in body size that was not explained by traffic noise. We calculated the mean, standard deviation and the 2.5th and 97.5th percentiles of the posterior distribution of the model coefficients. The latter two values were used to represent the $95 \%$ Bayesian confidence interval, $\mathrm{i}$. e., $95 \%$ credible interval, of the estimate.

\section{Effect of traffic noise and temperature on call frequency}

We used hierarchical, Bayesian multiple linear regression in OpenBUGS to model the effects of traffic noise and ambient temperature on call frequency. The model for $L$. ewingii included prior information on the effect of temperature on call frequency (Harrison 1987), whereas the model for $C$. signifera included only flat priors to reflect an absence of prior information. Because frogs are ectothermic, temperature influences both the production of acoustic signals and signal reception (Gerhardt and Mudry 1980, Narins 2001), and the frequency or pitch of frog calls is known to increase with body temperature. In small frogs such as $L$. ewingii and $C$. signifera, body temperature will approximate ambient temperature (Littlejohn 1965). We used wet bulb temperature as an explanatory variable in the $L$. ewingii model because this species tends to call from perches above the water, and water temperature for the $C$. signifera model because this species tends to call while sitting in the water.

\section{Comparison of the frequency shift with noise in} birds and frogs

Four studies have shown an increase in the frequency of bird song with increasing urban noise (Slabbekoorn and Peet 2003, Fernández-Juricic et al. 2005, Wood and Yezerinac 2006, Slabbekoorn and den Boer-Visser 2006). We selected the first three of these for our comparison, because they provide information on a continuous linear relationship between song frequency and noise level. From these published data and the results of our regression models, we calculated the proportional effect of noise on signal frequency as percent change in frequency/dB of noise for five species: the great tit Parus major (Slabbekoorn and Peet 2003), the house finch Carpodacus mexicanus (Fernández-Juricic et al. 2005), the song sparrow Melospiza melodia (Wood and Yezerinac 2006), L. ewingii, and $C$. signifera.

\section{Mathematical modeling of active distance in Litoria ewingii}

The active distance of an acoustic signal in noise can be estimated from the amplitude or loudness of the signal, the propagation or attenuation of the signal as it moves through the landscape, and the auditory threshold of the receiver in noise, i.e., how loud the signal must be for the receiver to detect it (Parris 2002). We estimated the effect of the observed frequency shift on the active distance of the call of $L$. ewingii using the following information: (1) the maximum amplitude of $L$. ewingii calls (Loftus-Hills and Littlejohn 1971); (2) a mathematical model of call propagation in the spring peeper Pseudacris crucifer (Parris 2002); (3) the auditory threshold of $L$. ewingii across the frequency spectrum in the absence of noise (LoftusHills and Johnstone 1969, Loftus-Hills 1973) and the masking susceptibility of auditory nerve fibres, i.e., the increase in the auditory threshold, in the green treefrog Hyla cinerea in broad-band noise (Ehret and Capranica 1980); and (4) the frequency 
distribution of traffic noise, estimated from a digital recording of noise taken adjacent to the Eastern Freeway in Melbourne (Fig. 4). The advertisement call of $P$. crucifer has similar spectral properties to the call of $L$. ewingii, so it is reasonable to expect that the two calls would propagate similarly in the environment.

We used the following parameters in the mathematical model: a male frog calling from an elevated position $50 \mathrm{~cm}$ above the ground at an amplitude of $91 \mathrm{~dB}$ root mean squared (RMS) SPL at $50 \mathrm{~cm}$, with the hearing thresholds of the female receiver set at 63.8 and $62.4 \mathrm{~dB}$ SPL. These two values were the expected hearing thresholds before and after the observed frequency shift in the male's call at the noisiest site included in the study. The difference between the active distances of the call at the two hearing thresholds gave the change in active distance with the frequency shift in traffic noise. We also used the equation presented by Parris (2002) to estimate the increase in nightly energy expenditure by male frogs if they called at a higher amplitude, rather than calling at a higher pitch, to reduce the masking effect of traffic noise. Please refer to Appendix 3 for more information on the methods used.

\section{RESULTS}

\section{Body size of Litoria ewingii}

The predicted change in the body size of males of Litoria ewingii with increasing traffic noise at a site was small, although wide credible intervals indicate considerable uncertainty regarding the size of the effect (Fig. 5). The model predicted an average decrease in snout-vent length of $0.034 \mathrm{~mm} / \mathrm{dB}$ of traffic noise $(95 \%$ CI: $-0.28-0.18)$, which corresponds to a decrease of $0.73 \mathrm{~mm}(2.3 \%)$ in snout-vent length between sites with traffic noise levels of 47 and $68 \mathrm{~dB}(\mathrm{~A}) \mathrm{L}_{10} 18 \mathrm{hr}$ SPL, respectively (Fig. 5). Based on data from 15 species of Australian frogs (Loftus-Hills 1973), this change in body size would confer an increase of approximately $40 \mathrm{~Hz}$ in the dominant frequency of a frog's call. However, more data are required, particularly at very quiet and very noisy sites, to be confident of the nature and magnitude of the relationship between traffic noise and body size in L. ewingii.

\section{Effect of traffic noise on the frequency of calls}

Regression modeling indicated that males of Litoria ewingii called at a higher pitch at sites with higher levels of traffic noise. The predicted increase in the dominant frequency of $L$. ewingii calls was $4.1 \mathrm{~Hz} /$ $\mathrm{dB}$ of traffic noise (95\% CI: -1.2 - 9.6; Table 1; Fig. 6A). This represents an increase of $123 \mathrm{~Hz}$ over the range of noise levels observed, and a proportional increase of $0.17 \% / \mathrm{dB}$ of traffic noise or $5.0 \%$ over the range of data. The lower frequency of the advertisement call of Crinia signifera was also predicted to increase with traffic noise, but to a lesser extent: $1.5 \mathrm{~Hz} / \mathrm{dB}$ of traffic noise $(95 \%$ CI: -5.8 - 8.8; Table 1; Fig. 6B). This corresponds to an increase of $63 \mathrm{~Hz}$ over the range of traffic noise levels observed, and a proportional frequency shift of $0.061 \% / \mathrm{dB}$ of traffic noise, or $2.3 \%$ in total. Given the wide credible intervals around this prediction, the effect of traffic noise on the lower frequency of $C$. signifera calls is very uncertain, and further data are required to clarify the relationship. The predicted effect of traffic noise on the upper frequency of $C$. signifera calls was close to zero (-0.44 Hz/dB, 95\% CI: -8.9 - 8.1), consistent with our expectation that the upper frequency would experience less acoustic interference from traffic noise and would therefore be less likely to change in response. The average effect was actually negative, suggesting a decrease in frequency with increasing traffic noise, but wide credible intervals indicate that this result, too, is very uncertain. When considering the lower frequency of $C$. signifera calls, the average effect of traffic noise on call frequency in $L$. ewingii and $C$. signifera was an increase of $3.0 \mathrm{~Hz} / \mathrm{dB}$ of traffic noise $(95 \% \mathrm{CI}$ : -1.0 7.0).

\section{Effect of temperature on the frequency of calls}

Litoria ewingii clearly called at a higher pitch in warmer conditions, with a predicted increase in the dominant frequency of its advertisement call of 21.5 $\mathrm{Hz} /{ }^{\circ} \mathrm{C}$ of wet bulb temperature (95\% CI: 10.8 - 32.4; Table 1; Fig. 7A). Both the lower and upper frequencies of the advertisement call of $C$. signifera were also predicted to increase with temperature, but the effect was less certain. Regression modeling estimated an increase of $10.3 \mathrm{~Hz} /{ }^{\circ} \mathrm{C}$ of water temperature (95\% CI: -6.2 - 26.2; Table 1; Fig. 7B) for the lower frequency and $17.3 \mathrm{~Hz} /{ }^{\circ} \mathrm{C}(95 \%$ CI: $-1.8-37.1)$ for the upper frequency. As for the 
Fig. 4. Power spectrum of traffic noise used in the mathematical model of the active distance of Litoria ewingii calls, corrected for an overall SPL of $77 \mathrm{~dB}$.

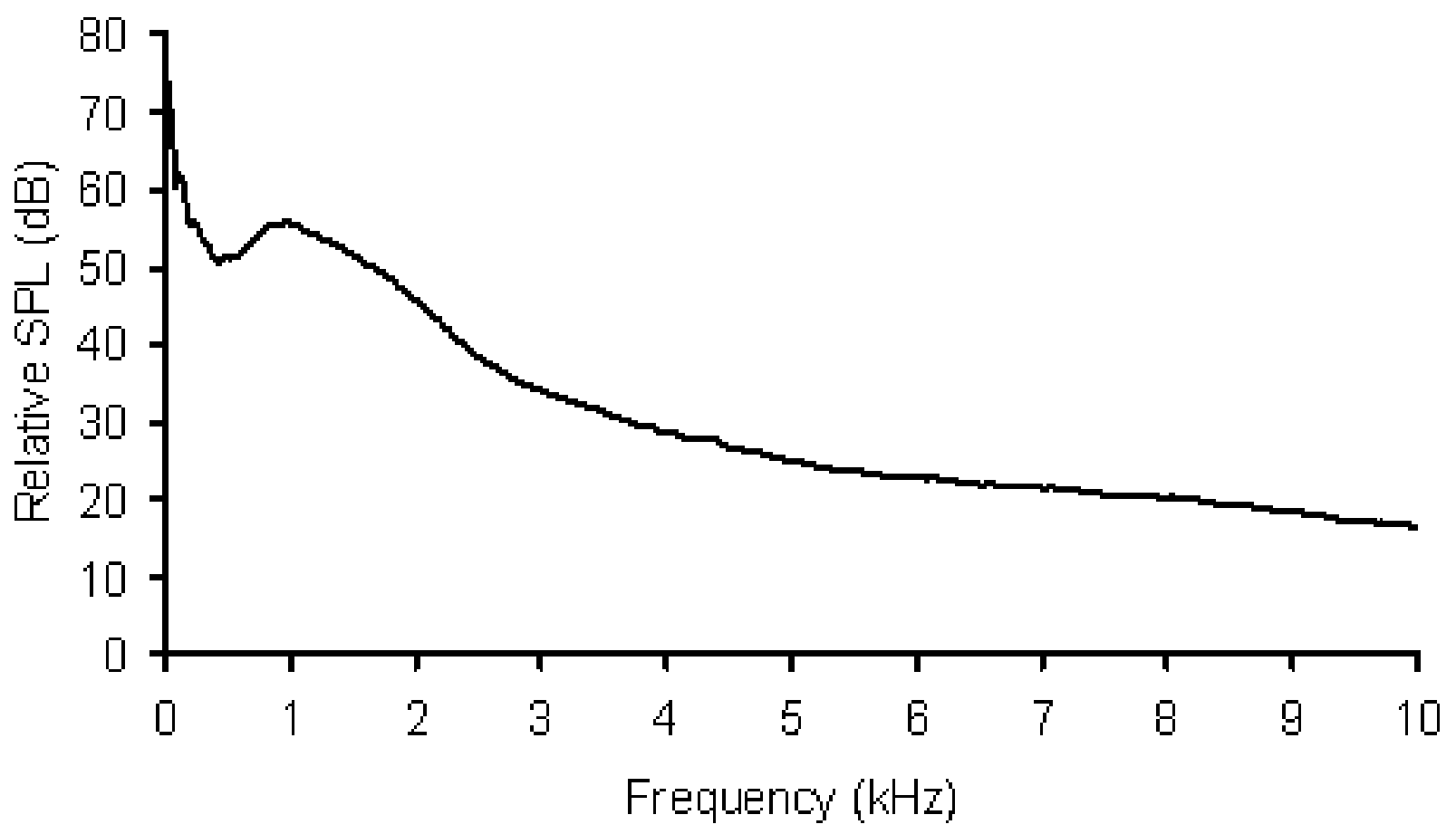

effect of traffic noise on call frequency in $C$. signifera, the effect of temperature needs to be clarified with additional data. The model for $L$. ewingii included prior information on the effect of temperature on call frequency, with a mean of 37.9 $\mathrm{Hz} /{ }^{\circ} \mathrm{C}$, a standard error of $12.1 \mathrm{~Hz} /{ }^{\circ} \mathrm{C}$, and a sample size of 28 individuals (Harrison 1987). Both the prior information and our data contributed to the final estimate of the effect (the posterior distribution), but our data contributed approximately four times as much information as the prior.

\section{Comparison with the effect of urban noise on the frequency of bird song}

The proportional effect of urban noise on signal frequency in birds appears to be larger than the effect we observed in frogs (Fig. 8). The effect of urban noise on the minimum frequency of $M$. melodia song is definitely larger than the effect of traffic noise on the dominant frequency of $L$. ewingii calls and the lower frequency of $C$. signifera calls, whereas the effect of noise on the song of $C$. mexicanus and $P$. major is likely to be larger. The proportional effect of traffic noise on signal frequency was similar in the two frog species and was estimated more precisely than the effect in birds as indicated by the narrower confidence/credible intervals (Fig. 8).

\section{The active distance of Litoria ewingii calls in noise}

Mathematical modeling demonstrated that the increase in call frequency with traffic noise observed in L. ewingii would provide a substantial benefit to the caller. The active distance of the call was predicted to increase by approximately $24 \%$, from 19.2 to $23.8 \mathrm{~m}$, in the maximum traffic noise level observed during the study (77 dB SPL). This is because of a decrease of approximately $1.4 \mathrm{~dB}$ in the sound-pressure level of traffic noise when moving up the frequency spectrum from 2461 to $2584 \mathrm{~Hz}$ (Fig. 4), resulting in less effective masking of the higher-frequency call. If one assumes that a 
Fig. 5. Body size expressed as snout-vent length (SVL) of Litoria ewingii as a function of traffic noise $(n=12)$. The solid line shows the predicted relationship, dashed lines the $95 \%$ credible intervals, and circles the mean SVL observed at each site.

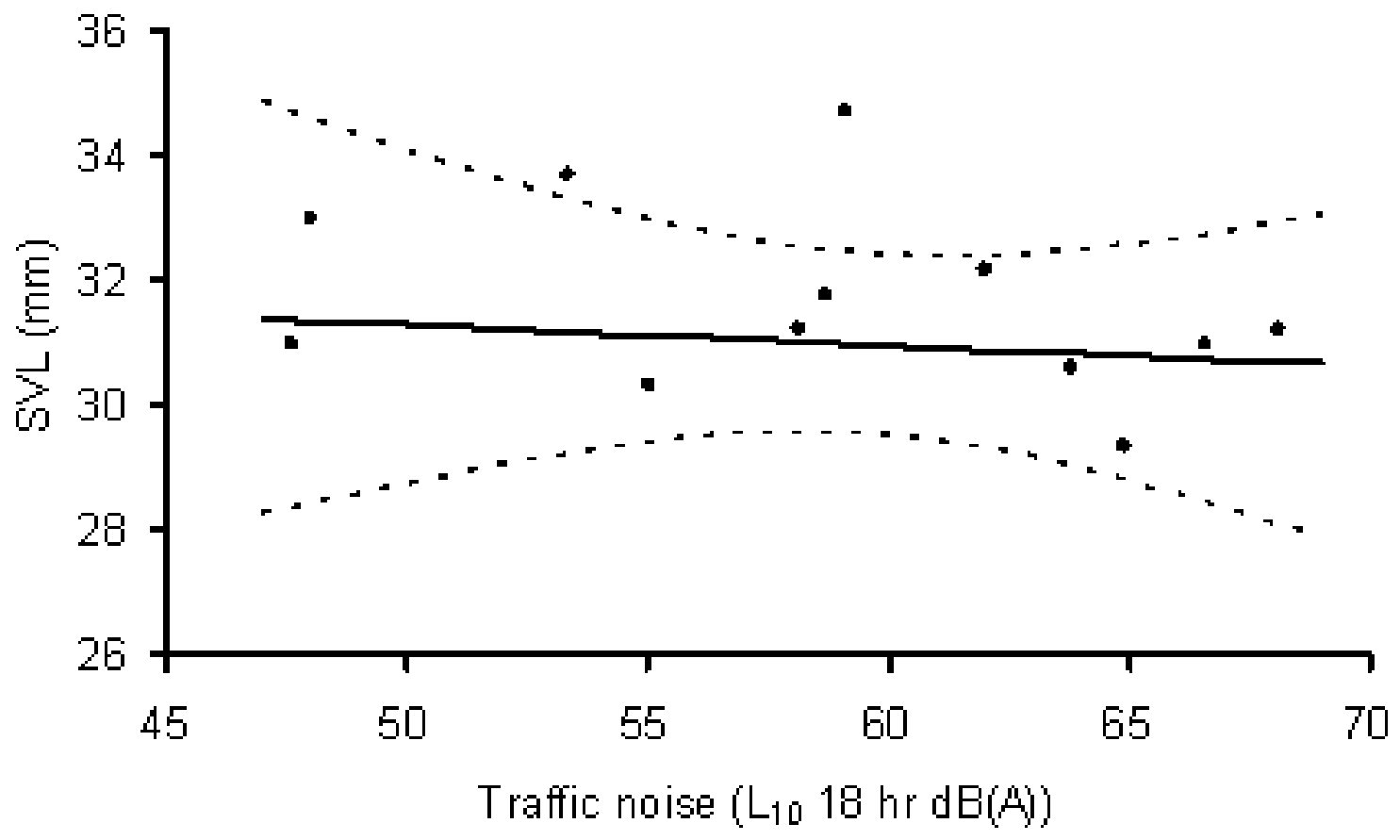

calling L. ewingii is an omnidirectional radiator of sound (Prestwich et al. 1989), the active area of the call in traffic noise would increase by approximately $54 \%$, from 1152 to $1772 \mathrm{~m}^{2}$, with the observed frequency shift. However, in the absence of background noise, a call of $91 \mathrm{~dB}$ RMS SPL is predicted to have an active distance of approximately $74.5 \mathrm{~m}$ and an active area of 17,440 $\mathrm{m}^{2}$; thus, the frequency shift only partially compensates for the masking effect of traffic noise. Calling at a higher amplitude is another strategy that frogs could use to reduce masking from traffic noise, although one that comes at a substantial energetic cost. To obtain the same release from masking provided by a $123-\mathrm{Hz}$ frequency shift, a calling frog would increase its nightly energy expenditure by approximately $37 \%$, from an estimated 132 to 180 $\mathrm{J}$ with a 1.4-dB increase in the amplitude of its call from 91 to $92.4 \mathrm{~dB}$ RMS SPL and $3 \mathrm{hr}$ of calling/ night (Parris 2002).

\section{DISCUSSION}

\section{Effect of traffic noise on the frequency of calls}

We observed an increase of approximately $125 \mathrm{~Hz}$ in the dominant frequency of Litoria ewingii calls between the sites with the lowest and highest levels of traffic noise. Based on laboratory experiments with other frog species, differences in frequency of this size would be clearly detectable by conspecific females in the absence of masking noise (Ryan 1983, Gerhardt 1991). However, it remains to be seen whether such a difference would influence mate choice by female frogs in a noisy field environment (Wollerman and Wiley 2002). Barrass (1985) observed an increase in the fundamental frequency of Bufo woodhousei and Hyla cinerea calls of $0.18 \% / \mathrm{dB}$ and $0.61 \% / \mathrm{dB}$ of traffic noise, respectively, between one site with a moderate level of traffic noise, i.e., an hourly equivalent sound level $($ Leq $[1 \mathrm{hr}])=53.8 \mathrm{~dB}$ SPL, and a second, noisier site near an interstate highway (Leq [1 hr] $=74.2$ dB SPL) in Texas, USA. Because of the unreplicated 
Fig. 6. The effect of traffic noise on the frequency of frog calls. (A) Dominant frequency of the advertisement call of Litoria ewingii, with wet bulb temperature held constant at $10^{\circ} \mathrm{C}(n=24)$. (B) Lower frequency of the advertisement call of Crinia signifera, with water temperature held constant at $15^{\circ} \mathrm{C}(n=28)$. Solid lines show the predicted relationships, dashed lines the $95 \%$ credible intervals, and circles the mean call frequency observed at each site, corrected for temperature.
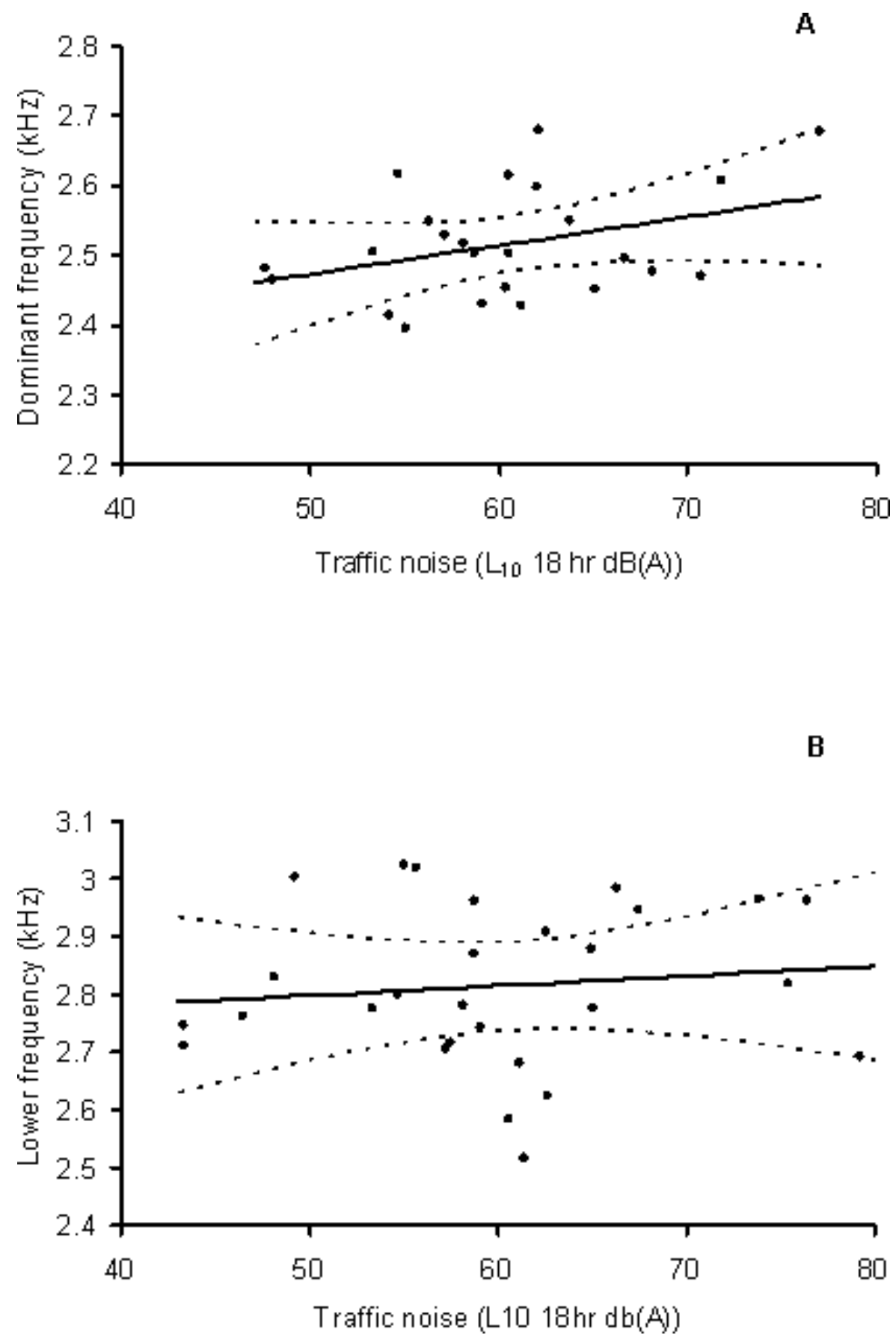
Table 1. Coefficients (mean, standard deviation, and 2.5th and 97.5th percentiles) of the variables included in the regression models of call frequency as a function of traffic noise, expressed as $\mathrm{L}_{10} 18 \mathrm{hr} \mathrm{dB}(\mathrm{A}) \mathrm{SPL}$, and temperature expressed as degrees Centigrade. Coefficients are shown for the models of the dominant frequency of the call of Litoria ewingii and the lower frequency of the call of Crinia signifera.

\begin{tabular}{lcccccccc}
\hline \hline & \multicolumn{3}{c}{ Litoria ewingii } & & \multicolumn{4}{c}{ Crinia signifera } \\
Variable & Mean & SD & $2.5 \%$ & $97.5 \%$ & Mean & SD & $2.5 \%$ & $97.5 \%$ \\
\hline Constant & 2489 & 19.1 & 2452 & 2527 & 2835 & 34.2 & 2766 & 2901 \\
Traffic noise & 4.15 & 2.76 & -1.24 & 9.60 & 1.50 & 3.68 & -5.76 & 8.77 \\
Temperature & 21.5 & 5.49 & 10.8 & 32.4 & 10.3 & 8.22 & -6.16 & 26.2 \\
\hline
\end{tabular}

nature of his study, these results must be viewed with caution. However, they suggest that the phenomenon of frogs calling at a higher pitch in traffic noise may extend beyond $L$. ewingii. Although our statistical modeling indicated that $C$. signifera may also call at a higher pitch in traffic noise, more data are required to be certain of the relationship. The broadband nature of its advertisement call may make a frequency shift in noise a less useful strategy for $C$. signifera to adopt, or more difficult to identify with the methods used in our study. In general, broadband signals are harder to detect in noise than tonal signals, because the energy in the signal is spread out over a wide range of frequencies (Warren et al. 2006).

The predicted increases in signal frequency with traffic noise in $L$. ewingii and $C$. signifera are smaller than those seen in birds (Slabbekoorn and Peet 2003, Fernández-Juricic et al. 2005, Wood and Yezerinac 2006; Fig. 8), as could be expected from the different ways that acoustic signals develop in the two groups. Songbirds learn their songs from parents, neighbors, and other associates, and some species continue to incorporate new songs into their repertoire throughout their lives (Hultsch and Todt 2004). Song dialects can develop quickly in songbirds and tend to reflect the social relationships among birds rather than genotypic differences between populations (Kroodsma 2004). Lowfrequency components of songs will be harder to detect in noisy urban habitats and may not be learned by other birds (Slabbekoorn and Peet 2003, Brumm 2006). Consequently, new song dialects with improved detectability in noise could develop fairly rapidly in urban populations (Slabbekoorn and den Boer-Visser 2006). Songbirds can also change other song characteristics such as amplitude and redundancy, i.e., the level of repetition within a song, as a short-term response to noise (Brumm 2004, Brumm and Slater 2006), although short-term changes in song frequency in noise have not been demonstrated. Songbirds could be expected to show a faster and/or larger frequency shift in response to acoustic masking by traffic noise than frogs, which do not learn their calls. In frogs, a substantial population-level shift in call frequency may take many generations to manifest. Populations exposed to traffic noise for longer than the minimum of 20 yr used in our study might demonstrate a larger frequency shift than those we observed.

\section{The active distance of advertisement calls in noise}

Mathematical modeling indicated that the frequency shift in $L$. ewingii would substantially increase the active distance of its advertisement call in traffic noise. Furthermore, the alternative strategy of calling at a higher amplitude to reduce acoustic interference would incur a substantial energetic cost. These results suggest that calling at a higher pitch is a better long-term strategy for reducing acoustic interference from traffic noise than calling more loudly, assuming that the higher-pitched call is still reasonably attractive to females. The number of nights a frog spends calling at a breeding site, known as chorus tenure, explains much of the variation in male mating success across many 
Fig. 7. The effect of temperature on the frequency of frog calls, with traffic noise held constant at $50 \mathrm{~dB}$ (A) L10 $18 \mathrm{hr}$ SPL. (A) Dominant frequency of the advertisement call of Litoria ewingii as a function of wet bulb temperature $(n=24)$. (B) Lower frequency of the advertisement call of Crinia signifera as a function of water temperature $(n=28)$. Solid lines show the predicted relationships, dashed lines the $95 \%$ credible intervals, and circles the mean call frequency observed at each site, corrected for traffic noise.

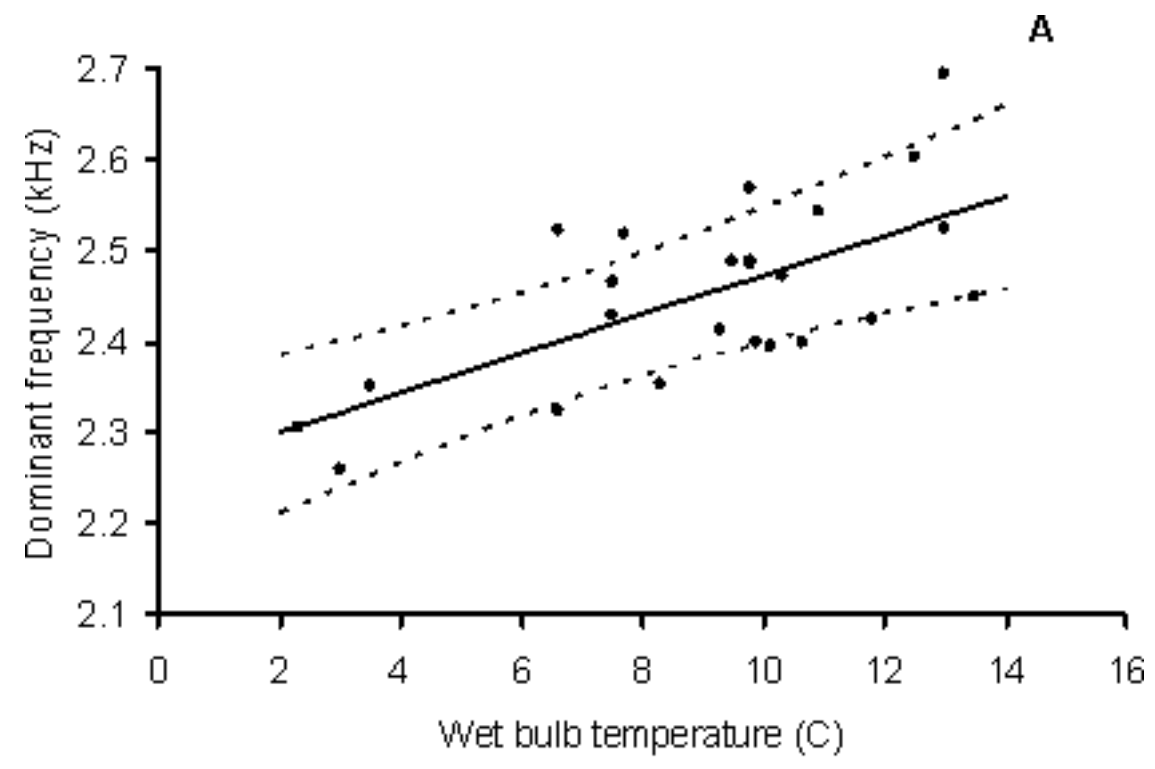

B

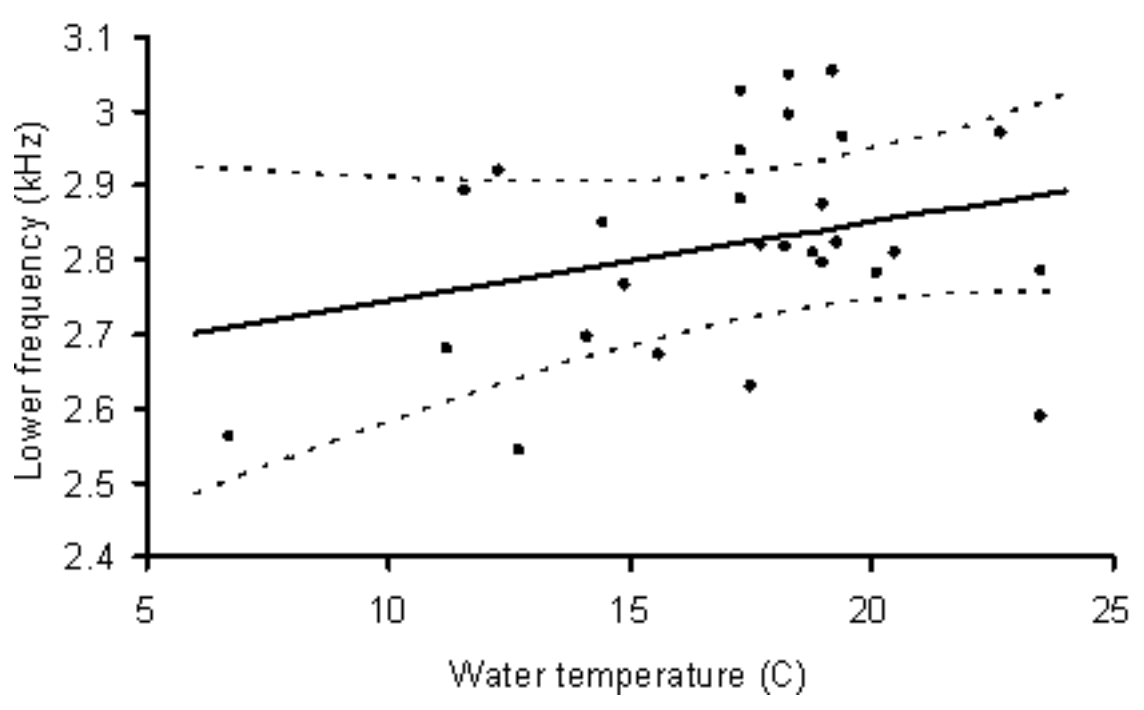


Fig. 8. Comparison of the proportional effect of noise on the frequency of birdsong and frog calls across five species (mean effect with 95\% confidence/credible intervals). Species: Melospiza melodia (Wood and Yezerinac 2006), Carpodacus mexicanus (Fernández-Juricic et al. 2005), Parus major (Slabbekoorn and Peet 2003), and Litoria ewingii and Crinia signifera (this study).

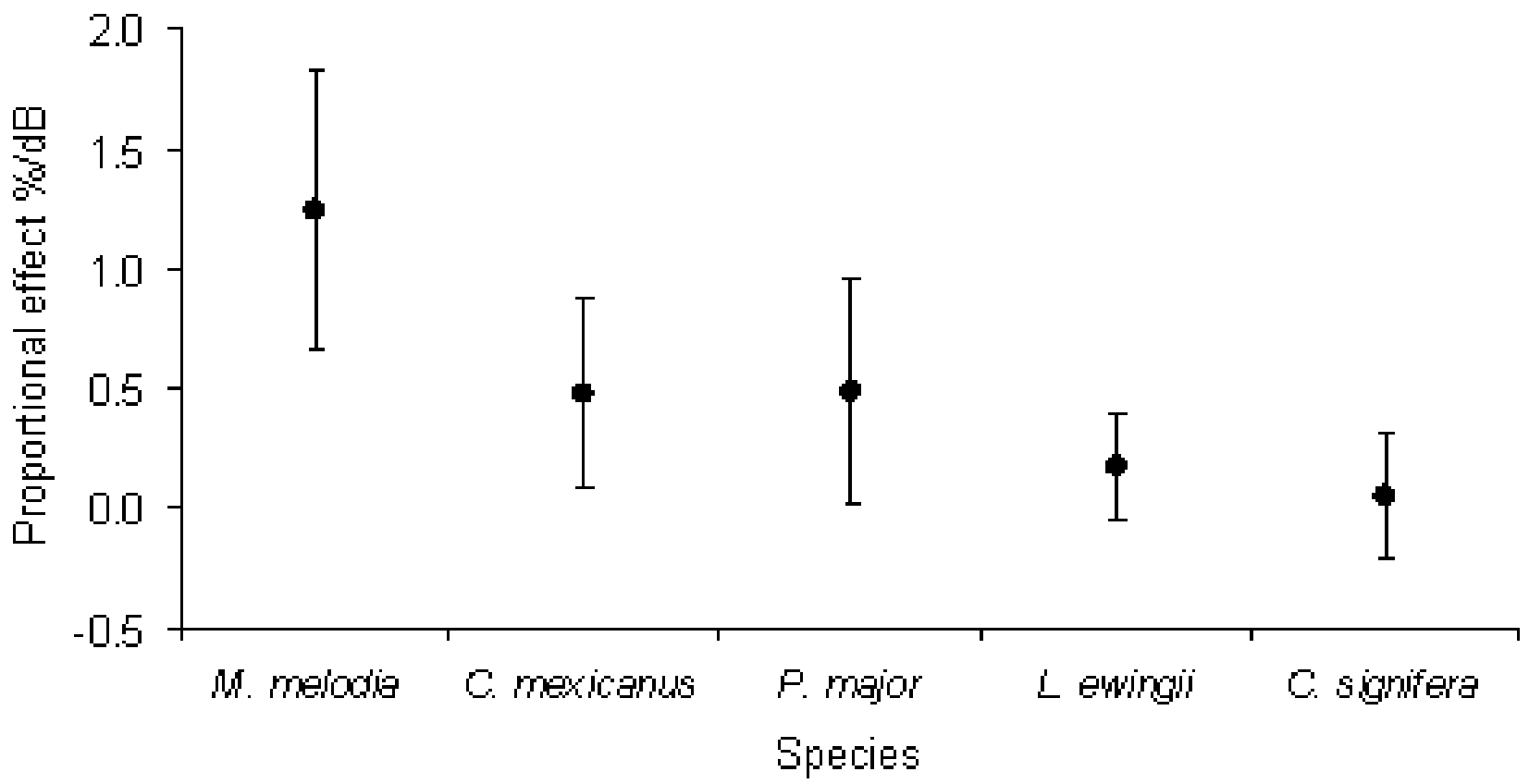

species of prolonged breeders: the longer the tenure, the greater the probability of obtaining at least one mate (Wells 2007). Chorus tenure is limited by a male's energy reserves (Murphy 1994), so that calling louder in noisy conditions is likely to reduce chorus tenure, possibly reducing a male's overall mating success. The predicted $37 \%$ increase in energy expended with a $1.4-\mathrm{dB}$ increase in call amplitude would either reduce the number of hours per night or the number of nights spent calling in a chorus.

Our mathematical model is based on empirical measurements of call attenuation in Pseudacris crucifer from North America (Brenowitz et al. 1984) and information on the masking effect of noise in Hyla cinerea (Ehret and Capranica 1980). It therefore assumes that call attenuation and masking in L. ewingii are similar to those observed in $P$. crucifer and $H$. cinerea, respectively. Pseudacris crucifer and L. ewingii are both small frogs of the family Hylidae. Their advertisement calls cover a narrow spectral band with a dominant frequency of approximately $2.2-2.8 \mathrm{kHz}$, so it is reasonable to assume that they would attenuate similarly. Further, although Ehret and Capranica (1980) presented data on masking of advertisement calls by broadband noise, Bee and Swanson (2007) showed that the masking effect of traffic noise was very similar. They found that the spectrum level of the call of $H$. chrysoscelis needed to be $25 \mathrm{~dB}$ above the level of the traffic noise at the dominant frequency of the call for the female frogs to detect and move toward it, based on the average LCeq value for traffic noise in the $1 / 3$ octave band with a center frequency of $2 \mathrm{kHz}$.

\section{Possible mechanisms underlying the frequency shift}

Because frog calls are considered to be innate rather than learned, a frequency shift in a frog population exposed to traffic noise could represent an evolutionary adaptation to noisy conditions. If this were the case, the frequency shift would take a 
number of generations to manifest; how many would depend on the strength of the selection pressure for higher-pitched calls. Alternatively, the frequency shift observed in Litoria ewingii might represent a short-term, plastic response to noisy conditions. There is some evidence of plasticity in the frequency of frog calls, with individual males of certain species known to call at a lower pitch in response to the calls of other males nearby (Lopez et al. 1988, Wagner 1989, Howard and Young 1998, Giacoma and Castellano 2001, Owen and Gordon 2005). However, there is no evidence that frogs can increase the frequency of their calls as a short-term response to noise. Field or laboratory experiments to measure call frequency within individuals before and after exposure to noise are required to assess this hypothesis. If males of our study species normally lower the frequency of their advertisement call during interactions with rivals, masking by traffic noise could interfere with these interactions because males would have difficulty hearing each other. This would then lead to males calling at a higher average frequency at noisy sites than at quiet sites. In a playback experiment, Harrison (1987) found that L. ewingii males did not change the pitch of their advertisement call in response to the calls of other males. To our knowledge, there are no data available on the response of $C$. signifera males in this situation.

Other possible explanations for the observed frequency shift with traffic noise are that males from noisier sites are consistently smaller than males from quieter sites, or that they call at a higher amplitude in noisy conditions despite the energetic cost, with a concomitant increase in call frequency (Martin 1971, Lopez et al. 1988). Our analysis of the body size of $L$. ewingii as a function of traffic noise was inconclusive; although we did not find strong evidence of an important decrease in body size with increasing traffic noise, it is possible that a larger data set would reveal one. We accounted for random site-to-site variation in the size distribution of frogs during modeling of the effect of traffic noise on call frequency, but not for a systematic decrease in body size with increasing traffic noise. Noisier sites may experience higher levels of adult mortality from road kill or other urban hazards, skewing the distribution of body sizes. Alternatively, traffic noise may be negatively correlated with the quality of breeding habitat at a site. Poorer quality habitat could reduce the size of frogs at metamorphosis, and thus their adult body size (Berven 1990). Reliable measurements of the amplitude of acoustic signals in the field would be needed to observe an amplitude shift in response to traffic noise. These could be obtained using careful sampling protocols that enable the distance between a calling frog and the microphone to be estimated accurately (Brumm 2004).

\section{Implications for the ecology, evolution, and conservation of frogs in noisy urban habitats}

Although calling at a higher frequency in traffic noise will increase the distance over which a male can be heard, it may not be the best strategy for attracting females for mating. When presented with a choice, female frogs of some species prefer lowerpitched calls, which indicate larger and/or more experienced males (Ryan 1986, Pombal et al. 1994, Wollerman 1998, Felton et al. 2006). If male frogs calling at a higher pitch in traffic noise were a general phenomenon, this would present an intriguing trade-off between audibility and attractiveness to potential mates in these species. This trade-off has also been hypothesized for individuals of Parus major that sing at a higher pitch in urban noise (Slabbekoorn and Ripmeester 2008). If male frogs do not call at a higher pitch in traffic noise, females may have difficulty locating mates, potentially leading to reduced breeding success and population declines over time. In addition, females may expend extra energy and expose themselves to an increased risk of predation while searching for mates (Gerhardt 1991). If males do call at a higher pitch, they may make themselves less attractive to females and less imposing to rival males (Wagner 1989, Giacoma and Castellano 2001). Such a frequency shift could also lead to reduced territory sizes and/or a change in the rate of agonistic encounters between male frogs (Wagner 1989, Giacoma and Castellano 2001). Field studies of mating success as a function of call frequency in traffic-noisy habitats, and of changes in male-male interactions between quiet and noisy sites, are needed to elucidate these effects. It is unlikely that male frogs with advertisement calls below $3 \mathrm{kHz}$, such as our study species, could achieve a frequency shift large enough to counteract fully the acoustic interference caused by traffic noise; even if it were possible, it would not be advantageous if the innerear tuning of the receivers did not alter sufficiently (Ryan 1986). The frequency shift observed in $L$. ewingii increased the active distance of its call from approximately 19 to $24 \mathrm{~m}$, but this is still much less than the active distance of $74.5 \mathrm{~m}$ predicted in the 
absence of noise. Frogs exposed to high levels of traffic noise will suffer substantial acoustic interference, which, if translated into reduced breeding success, could eventually lead to the local extinction of populations in otherwise suitable habitats.

\section{CONCLUSION}

We found evidence that the spectral characteristics of $L$. ewingii calls are changing with increasing road-traffic noise, but insufficiently to reverse the masking effect of noise. Given the large and increasing proportion of habitats around the world that are affected by roads, traffic noise has the potential to affect many populations of frogs that are already vulnerable to threats such as habitat loss and fragmentation, pollution, and disease (Stuart et al. 2004). But how do we protect frogs and other acoustically communicating animals from traffic noise? Slabbekoorn and Ripmeester (2008) suggested solid sound barriers to protect birds from urban noise, but such barriers may prevent the movement of terrestrial animals through the landscape, leading to the isolation of populations (Forman and Alexander 1998, Forman et al. 2003). Solid sound barriers with regular overpasses or tunnels would reduce noise levels but still allow animals to cross the road, assuming that the animals in a given area will use these types of crossing structures. Dense vegetation along roadsides may also attenuate traffic noise and will probably be cheaper to install than solid barriers. Particularly in areas in which populations of endangered species are exposed to high levels of traffic noise, the use of such engineering measures may be a worthwhile management strategy.

Responses to this article can be read online at: http://www.ecologyandsociety.org/voll4/iss 1/art25/ responses/

\section{Acknowledgments:}

We thank Rob Clemens and Angela Schneider for collecting frog recordings, and the many volunteers who helped with field work. We are grateful to VicRoads, the Mornington Peninsula Shire, the Shires of Nillumbik and Yarra Ranges, and the Cities of Banyule, Casey, Darebin, Frankston, Hume, Melton, and Moreland for data on traffic volumes.
We thank Michael McCarthy for assistance with data analysis; Andrew Bennett, Henrik Brumm, Beth Dawson, Murray Littlejohn, Brian Sullivan, and Mark McDonnell for discussions; and Henrik Brumm, Fiona Fidler, Murray Littlejohn, and Michael McCarthy for comments on the manuscript. This research was approved by the Deakin University Animal Welfare Committee and supported by an ARC Discovery grant to K. M. P., the Baker Foundation, and the Applied Environmental Decision Analysis research hub. This hub is funded by the Commonwealth Environment Research Facilities (CERF) program, an Australian government initiative that promotes world-class, public-good research. M. V.-L. and J. M. A. N. made an equal contribution to this work.

\section{LITERATURE CITED}

Anderson, D. R., K. P. Burnham, and W. L. Thompson. 2000. Null hypothesis testing: problems, prevalence, and an alternative. Journal of Wildlife Management 64:912-923.

Asquith, A., and R. Altig. 1990. Male call frequency as a criterion for female choice in $\mathrm{Hyla}$ cinerea. Journal of Herpetology 24:198-201.

Barrass, A. N. 1985. The effects of highway traffic noise on the phonotactic and associated reproductive behaviour of selected anurans. Dissertation. Vanderbilt University, Nashville, Tennessee, USA.

Bee, M. A., S. A. Perrill, and P. C. Owen. 2000. Male green frogs lower the pitch of acoustic signals in defense of territories: a possible dishonest signal of size? Behavioral Ecology 11:169-177.

Bee, M. A., and E. M. Swanson. 2007. Auditory masking of anuran advertisement calls by road traffic noise. Animal Behaviour 74:1765-1776.

Berven, K. A. 1990. Factors affecting population fluctuations in larval and adult stages of the wood frog (Rana sylvatica). Ecology 71:1599-1608.

Brenowitz, E. A., W. Wilczynski, and H. H. Zakon. 1984. Acoustic communication in spring peepers: environmental and behavioral aspects. Journal of Comparative Physiology A 155:585-592. 
Brumm, H. 2004. The impact of environmental noise on song amplitude in a territorial bird. Journal of Animal Ecology 73:434-440.

Brumm, H. 2006. City birds have changed their tune. Current Biology 16:R1003-R1004.

Brumm, H., and H. Slabbekoorn. 2005. Acoustic communication in noise. Advances in the Study of Behaviour 35:151-209.

Clark, J. S. 2005. Why environmental scientists are becoming Bayesians. Ecology Letters 8:2-15.

Department of Transport Welsh Office. 1988. Calculation of road traffic noise. Her Majesty's Stationery Office, London, UK.

Ehret, G., and R. R. Capranica. 1980. Masking patterns and filter characteristics of auditory nerve fibers in the green treefrog (Hyla cinerea). Journal of Comparative Physiology 141:1-12.

Eigenbrod, F., S. J. Hecnar, and L. Fahrig. 2009. Quantifying the road-effect zone: threshold effects of a motorway on anuran populations in Ontario, Canada. Ecology and Society 14(1): 24. [online] URL: http://www.ecologyandsociety.org/vol14/iss1/ art24/.

Fellers, G. M. 1979. Aggression, territoriality, and mating behaviour in North American treefrogs. Animal Behaviour 27:107-119.

Felton, A., R. A. Alford, A. M. Felton, and L. Schwarzkopf. 2006. Multiple mate choice criteria and the importance of age for male mating success in the microhylid frog, Cophixalus ornatus. Behavioral Ecology and Sociobiology 59:786-795.

Fernández-Juricic, E., R. Poston, K. De Collibus, T. Morgan, B. Bastain, C. Martin, K. Jones, and R. Treminio. 2005. Microhabitat selection and singing behaviour patterns of male house finches (Carpodacus mexicanus) in urban parks in a heavily urbanized landscape in the western U.S. Urban Habitats 3:49-69.

Fidler F., M. A. Burgman, G. Cumming, R. Buttrose, and N. Thomason. 2006. Impact of criticism of null-hypothesis significance testing on statistical reporting practices in conservation biology. Conservation Biology 20:1539-1544.
Forman, R. T. T., and L. E. Alexander. 1998. Roads and their major ecological effects. Annual Review of Ecology and Systematics 29:207-231.

Forman, R. T. T., D. Sperling, J. A. Bissonette, A. P. Clevenger, C. D. Cutshall, V. H. Dale, L. Fahrig, R. France, C. R. Goldman, K. Heanue, J. A. Jones, F. J. Swanson, T. Turrentine, and T. C. Winter. 2003. Road ecology: science and solutions. Island Press, Washington D.C., USA.

Fuller, R. A., P. H. Warren, and K. J. Gaston. 2007. Daytime noise predicts nocturnal singing in urban robins. Biology Letters 3:368-370.

Gerhardt, H. C. 1991. Female mate choice in treefrogs: static and dynamic acoustic criteria. Animal Behaviour 42:615-635.

Gerhardt, H. C., and F. Huber, editors. 2002. Acoustic communication in insects and Anurans: common problems and diverse solutions. University of Chicago Press, Chicago, Illinois, USA.

Gerhardt, H. C., and G. M. Klump. 1988. Masking of acoustic signals by the chorus background noise in the green tree frog: a limitation on mate choice. Animal Behaviour 36:1247-1249.

Gerhardt, H. C., and K. M. Mudry. 1980. Temperature effects on frequency preferences and mating call frequencies in the green treefrog, $\mathrm{Hyla}$ cinerea (Anura: Hylidae). Journal of Comparative Physiology 137:1-6.

Giacoma, C., and S. Castellano. 2001. Advertisement call variation and speciation in the Bufo viridis complex. Pages 205-219 in M. J. Ryan, editor. Anuran communication. Smithsonian Institution Press, Washington D.C., USA.

Given, M. F. 1999. Frequency alteration of the advertisement call in the carpenter frog Rana virgatipes. Herpetologica 55:304-317.

Halliday, T. R. 2008. Why amphibians are important. International Zoo Yearbook 42:7-14.

Harrison, P.A. 1987. Vocal behaviour in the southeastern Australian tree frogs, Litoria ewingii and L. verreauxi (Anura: Hylidae). Dissertation. University of Melbourne, Melbourne, Australia. 
Hauser, M. D. 1996. The evolution of communication. MIT Press, Cambridge, Massachusetts, USA.

Heyer, W. R., M. A. Donnelly, R. W. McDiarmid, L. C. Hayek, and M. S. Foster, editors. 1994. Measuring and monitoring biological diversity: standard methods for amphibians. Smithsonian Institution Press, Washington D.C., USA.

Howard, R. D., and J. R. Young. 1998. Individual variation in male vocal traits and female mating preferences in Bufo americanus. Animal Behaviour 55:1165-1179.

Hultsch, H., and D. Todt. 2004. Learning to sing. Pages 80-107 in P. Marler and H. Slabbekoorn, editors. Nature's music: the science of birdsong. Academic Press, San Diego, California, USA.

Johnson, D. H. 1999. The insignificance of statistical significance testing. Journal of Wildlife Management 63:763-772.

Katti, M., and P. S. Warren. 2004. Tits, noise, and urban bioacoustics. Trends in Ecology and Evolution 19:109-110.

Kroodsma, D. 2004. The diversity and plasticity of birdsong. Pages 108-131 in P. Marler and $\mathrm{H}$. Slabbekoorn, editors. Nature's music: the science of birdsong. Academic Press, San Diego, California, USA.

Littlejohn, M. J. 1964. Geographic isolation and mating call differentiation in Crinia signifera. Evolution 18:262-266.

Littlejohn, M. J. 1965. Premating isolation in the Hyla ewingii complex (Anura: Hylidae).

Evolution 19:234-243.

Littlejohn, M. J., and J. R. Wright. 1997. Structure of the acoustic signals of Crinia glauerti (Anura: Myobatrachidae) from south-western Australia, and comparison with those of $C$. signifera from South Australia. Transactions of the Royal Society of South Australia 121:103-117.

Loftus-Hills, J. J. 1973. Comparative aspects of auditory function in Australian anurans. Australian Journal of Zoology 21:353-367.
Loftus-Hills, J. J., and B. M. Johnstone. 1969. Auditory function, communication, and the brainevoked response in anuran amphibians. Journal of the Acoustical Society of America 47:1131-1138.

Loftus-Hills, J. J., and M. J. Littlejohn. 1971. Mating-call sound intensities of anuran amphibians. Journal of the Acoustical Society of America 49:1327-1329.

Lopez, P. T., P. M. Narins, E. R. Lewis, and S. W. Moore. 1988. Acoustically induced call modification in the white-lipped frog, Leptodactylus albilabris. Animal Behaviour 36:1295-1308.

Mac Nally, R. C. 1981. On the reproductive energetics of chorusing males: energy depletion profiles, restoration and growth in two sympatric species of Ranidella (Anura). Oecologia 51:181-188.

Marten, K., and P. Marler. 1977. Sound transmission and its significance for animal vocalization. I. Temperate habitats. Behavioral Ecology and Sociobiology 2:271-290.

Martin, W. F. 1971. Mechanics of sound production in toads of the genus Bufo: passive elements. Journal of Experimental Zoology 176:273-294.

McCarthy, M. A. 2007. Bayesian methods for ecology. Cambridge University Press, Cambridge, UK.

Mitchell, N. J. 2001. Males call from wetter nests: effects of substrate water potential on reproductive behaviours of terrestrial toadlets. Proceedings of the Royal Society of London B 268:87-93.

Murphy, C. G. 1994. Determinants of chorus tenure in barking treefrogs (Hyla gratiosa). Behavioral Ecology and Sociobiology 34:285-294.

Narins, P. M. 2001. Ectothermy's last stand: hearing in the heat and cold. Pages 61-73 in M. J. Ryan, editor. Anuran communication. Smithsonian Institution Press, Washington D.C., USA.

Ovaska, K., and A. S. Rand. 2001. Courtship and reproductive behaviour of the frog Eleutherodactylus diastema (Anura: Leptodactylidae) in Gamboa, Panama. Journal of Herpetology 35:44-50.

Owen, P. C., and N. M. Gordon. 2005. The effect of perceived intruder proximity and resident body 
size on the aggressive responses of male green frogs, Rana clamitans (Anura: Ranidae). Behavioral Ecology and Sociobiology 58:446-455.

Paez, V. P., B. C. Bock, and A. S. Rand. 1993. Inhibition of evoked calling of Dendrobates pumilio due to acoustic interference from cicada calling. Biotropica 25:242-245.

Parris, K. M. 2002. More bang for your buck: the effect of caller position, habitat and chorus noise on the efficiency of calling in the spring peeper. Ecological Modeling 156:213-224.

Pfennig, K. S. 2000. Female spadefoot toads compromise on mate quality to ensure conspecific matings. Behavioral Ecology 11:220-227.

Pombal, J. P., I. Sazima, and F. B. Celio. 1994. Breeding behaviour of the Pumpkin toadlet, Brachycephalus ephippium (Brachycephalidae). Journal of Herpetology 28:516-519.

Prestwich, K. N. 1994. The energetics of acoustic signaling in anurans and insects. American Zoologist 34:625-643.

Prestwich, K. N., K. E. Brugger, and M. Topping. 1989. Energy and communication in three species of Hylid frogs: power input, power output and efficiency. Journal of Experimental Biology 144:53-80.

Ramer, J. D., T. A. Jenssen, and C. J. Hurst. 1983. Size-related variation in the advertisement call of Rana clamitans (Anura: Ranidae), and its effects on conspecific males. Copeia 1983:141-155.

Ryan, M. J. 1983. Sexual selection and communication in a Netropical frog, Physalaemus pustulosus. Evolution 37:261-272.

Ryan, M.J. 1986. Factors influencing the evolution of acoustic communication: biological constraints. Brain, Behavior and Evolution 28:70-82.

Schwartz, J. J. 2001. Call monitoring and interactive playback systems in the study of acoustic interactions among male anurans. Pages 183-205 in M. J. Ryan, editor. Anuran communication. Smithsonian Institution Press, Washington D.C., USA.

Slabbekoorn, H. 2004. Singing in the wild: the ecology of birdsong. Pages 178-205 in P. Marler and H. Slabbekoorn, editors. Nature's music: the science of birdsong. Academic Press, San Diego, California, USA.

Slabbekoorn, H., and A. den Boer-Visser. 2006. Cities change the songs of birds. Current Biology 16:2326-2331.

Slabbekoorn, H., and M. Peet. 2003. Birds sing at a higher pitch in urban noise. Nature 424:267.

Slabbekoorn, H., and E. A. P. Ripmeester. 2008. Birdsong and anthropogenic noise: implications and applications for conservation. Molecular Ecology 17:72-83.

Spiegelhalter, D., A. Thomas, N. Best, and D. Lunn. 2006. OpenBUGS User Manual Version 2.20. MRC Biostatistics Unit, Cambridge, UK.

Stuart, S. N., J. S. Chanson, N. A. Cox, B. E. Young, A. S. L. Rodrigues, D. L. Fischman, and R. W. Waller. 2004. Status and trends of amphibian declines and extinctions worldwide. Science 306:1783-1786.

Sullivan, B. K. 1983. Sexual selection in Woodhouse's toad (Bufo woodhousei). II. Female choice. Animal Behaviour 31:1011-1017.

Sullivan, B. K. 1992. Sexual selection and calling behaviour in the American toad Bufo americanus. Copeia 1992:1-7.

Sullivan, B. K., M. J. Ryan, and P. A. Verrell. 1996. Female choice and mating system structure. Pages 470-517 in H. Heatwole and B. K. Sullivan, editors. Amphibian biology. Volume 2. Social behaviour. Surrey Beatty, Chipping Norton, New South Wales, Australia.

Sun, J. W .C., and P. M. Narins. 2005. Anthropogenic sounds differentially affect amphibian call rate. Biological Conservation 121:419-427.

Wagner, W. E. 1989. Fighting, assessment, and frequency alteration in Blanchard's cricket frog. Behavioral Ecology and Sociobiology 25:429-436.

Warren, P. S., M. Katti, M. Ermann, and A. Brazel. 2006. Urban bioacoustics: it's not just noise. Animal Behaviour 71:491-502. 
Welch, A. M., R. D. Semlitsch, and H. C. Gerhardt. 1998. Call duration as an indicator of genetic quality in male gray tree frogs. Science 280:1928-1930.

Wells, K. D. 1977. The social behavior of anuran amphibians. Animal Behaviour 25:666-693.

Wells, K. D. 2007. The ecology and behavior of amphibians. University of Chicago Press, Chicago, Illinois, USA.

Wollerman, L. 1998. Stabilizing and directional preferences of female Hyla ebraccata for calls differing in static properties. Animal Behaviour 55 :1619-1630.

Wollerman, L., and R. H. Wiley. 2002. Background noise from a natural chorus alters female discrimination of male calls in a Neotropical frog. Animal Behaviour 63:15-22.

Wood, W. E., and S. M. Yezerinac. 2006. Song sparrow (Melospiza melodia) song varies with urban noise. The Auk 123:650-659.

Zweifel, R. G. 1968. Effects of temperature, body size, and hybridization on mating calls of toads, Bufo a. americanus and Bufo woodhousei fowleri. Copeia 1968:269-285. 
APPENDIX 1. Advertisement calls of two southern brown tree frogs Litoria ewingii, recorded at a wet bulb temperature of $13.5^{\circ} \mathrm{C}$. Crinia signifera is chorusing in the background. File in .wav format - will run in a variety of programs including Windows Media Player, iTunes, and Adobe Audition.

Appendix1 (File size: 3,495 KB) 
APPENDIX 2. Advertisement calls of the common eastern froglet Crinia signifera, duetting and in chorus, recorded at a water temperature of $15.6^{\circ} \mathrm{C}$. File in .wav format - will run in a variety of programs including Windows Media Player, iTunes, and Adobe Audition.

Appendix2 (File size: $2,816 \mathrm{~KB}$ ) 
Appendix 3. Additional Information on the Methods Used

Please click here to download file 'appendix3.pdf'. 